Sébastien Roux, No money, no honey. Économies intimes $d u$ tourisme sexuel en Thailande

Collection “Textes à l'appui/genre \& sexualité", éd. La Découverte, 2011, 268 pages

\title{
Philippe Duhamel
}

\section{OpenEdition \\ Journals}

Édition électronique

URL : http://journals.openedition.org/tourisme/208

DOI : $10.4000 /$ tourisme.208

ISSN : 2492-7503

\section{Éditeur}

Éditions touristiques européennes

\section{Édition imprimée}

Date de publication : 1 juin 2013

Pagination : 109-110

ISSN : 2109-5671

Référence électronique

Philippe Duhamel, «Sébastien Roux, No money, no honey. Économies intimes du tourisme sexuel en Thailande », Mondes du Tourisme [En ligne], 7 | 2013, mis en ligne le 30 septembre 2015, consulté le 22 septembre 2020. URL : http://journals.openedition.org/tourisme/208 ; DOI : https://doi.org/10.4000/ tourisme.208

Ce document a été généré automatiquement le 22 septembre 2020.

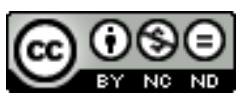

Mondes du tourisme est mis à disposition selon les termes de la licence Creative Commons Attribution - Pas d'Utilisation Commerciale - Pas de Modification 4.0 International. 


\section{Sébastien Roux, No money, no honey. Économies intimes du tourisme sexuel en Thailande}

Collection “Textes à l'appui/genre \& sexualité”, éd. La Découverte, 2011, 268 pages

\section{Philippe Duhamel}

\section{RÉFÉRENCE}

Sébastien Roux, No money, no honey. Économies intimes du tourisme sexuel en Thailande, coll. “Textes à l'appui/genre \& sexualité”, La Découverte, 2011.

1 Sébastien Roux propose ici un ouvrage de grand intérêt sur un thème majeur et sensible: le tourisme sexuel en Thaillande. De nombreux ouvrages et articles en différentes langues existent sur ce sujet et ce lieu et nous en avons rendu compte pour certains ( $c f$. Mondes $d u$ tourisme, $\mathrm{n}^{\circ}$ 2). La question se pose de savoir ce qu'apporte la présente publication, nourrie à partir d'une thèse soutenue en 2009 et centrée sur le quartier de Patpong, à Bangkok.

2 En tant que géographe, spécialiste non de la question sexuelle mais de la question touristique, cet ouvrage me paraît d'une grande utilité, d'une grande clairvoyance en ce qu'il remet en cause les images médiatiques et les discours moralisateurs sur le tourisme sexuel. L'idée ici n'est pas de cautionner une telle pratique, mais d'y réfléchir autrement: "Cet ouvrage entend ainsi développer une sociologie du tourisme sexuel attentive à la qualification des actes non par l'observateur mais par les agents concernés, ambitionnant de resituer les discours et les points de vue dans des contextes sociaux et historiques qui leur donnent sens" (pp. 12-13). De plus, l'auteur confère au tourisme un rôle particulier, ce qui, forcément, nous interpelle: "Les échanges sexuels en contexte touristique apparaissent comme un cas exemplaire où les normes morales habituelles [...] sont mises à mal par 
l'expérience pratique de la différence, révélant ainsi leur fragilité" (p. 12). Dès l'introduction, l'auteur évoque les difficultés méthodologiques inhérentes à son travail et propose une posture intègre et franche, sur le terrain comme dans l'écriture. Pour mener à bien sa réflexion, il opte pour un plan en deux parties très distinctes.

La première partie, intitulée "Ethnographie intime", porte sur une compréhension de la "diversité relationnelle" des relations entre les prostitué-e-s et les farangs [incarnation de la figure du "client"] dans des quartiers connus pour ce type d'échanges à Bangkok. Pour cela, l'auteur est en prise avec l'expérience du terrain et mène des entretiens. Le début de la partie est l'occasion, pour l'auteur, d'exprimer les difficultés et les "échecs" méthodologiques lorsqu'on veut entreprendre une recherche sur la prostitution. Sa posture montre, d'entrée de jeu, une manière d'être et de faire adaptée au sujet. Aussi ne sommes-nous pas étonnés de ses résultats. Il propose une lecture différente de ce que les médias et les ONG relaient comme information sur la prostitution en Asie du Sud-Est. Au-delà de ce "mainstream", les échanges menés, même s'ils restent limités en nombre, apparaissent exemplaires de la variété des situations et de ce qu'elles peuvent induire/impliquer comme degré d'engagements entre les prostitué-e-s et les farangs. Ici, sont mises en avant les ambiguïtés de cette relation où l'on sort du couple dominants-dominés pour proposer des logiques fondées sur des objectifs différents que l'on pourrait qualifier de gains réciproques, d'échanges. On avance sans fard dans cet univers et les propos des prostitué-e-s comme des farangs sont là pour nous montrer que, même si l'absurde et le sordide existent, l'image médiatique et la morale véhiculée ne rendent pas compte de l'ensemble des situations.

4 La deuxième partie, "Généalogie d'un interdit", relève d'un objectif et d'une méthodologie très différents. L'auteur entend y mener "une critique historique ou plus exactement généalogique pour saisir comment la catégorie [tourisme sexuel] s'est progressivement constituée" et y expliquer que "l'apparente univocité de l'expression ne doit pas faire oublier les luttes qui l'ont traversée et l'évolution des frontières de son objet" (p.145). Cette approche thématique et chronologique distingue la période 1989-1996 comme moment fort de basculement à l'échelle mondiale et à l'échelle thaïlandaise dans la prise en compte de la prostitution et dans la lutte contre celle-ci. Dans un contexte de diffusion du sida, le lien sanitaire et politique s'est constitué de manière étroite pour aboutir à une normalisation de la prostitution et à un glissement progressif vers d'autres enjeux, et notamment le TSIE (tourisme sexuel impliquant des enfants). La lecture de cette deuxième partie permet de comprendre la chronologie et les modalités d'élaboration d'une prise de conscience mondiale pour cette catégorie aujourd'hui très clairement identifié : le tourisme sexuel. Passionnant, ce développement opte par une narration qui tranche avec la partie précédente. Mais on saisit mal parfois d'où provient l'information et quelle légitimité accorder au discours proposé, en dépit de son intérêt évident.

5 Cet ouvrage est d'une lecture utile; le style en est souvent direct, voire percutant. Il apporte un regard "neuf" sur le sujet en proposant une analyse inédite et pertinente. Partir de l'étude de cas des prostitué-e-s et des farangs permet d'ouvrir à des réflexions et des enjeux essentiels à la société : "les évolutions contemporaines du politique" (p. 260). Ici comme ailleurs, ce livre montre que l'approche et la connaissance du tourisme, quelle que soit la facette qui en est mobilisée, est un outil d'intelligence du monde. Et, dans le cas présent, une intelligence fine et profondément humaine. Ce qui est une 
véritable prouesse car cet ouvrage touche à un sujet évoquant la facette la plus difficile à saisir de notre humanité : l'intime et la sexualité.

\section{AUTEURS}

\section{PHILIPPE DUHAMEL}

Université d'Angers 